\title{
AMERICANS’ CRASH HISTORIES AND OPINIONS ON SAFETY POLICY
}

\author{
T. Donna Chen \\ The University of Texas at Austin \\ 6.9 E. Cockrell Jr. Hall, Austin, TX 78712-1076 \\ donna.chen@utexas.edu \\ Kara M. Kockelman \\ Professor and William J. Murray Jr. Fellow \\ Department of Civil, Architectural and Environmental Engineering \\ The University of Texas at Austin \\ kkockelm@mail.utexas.edu \\ Phone: 512-471-0210 \\ This is a pre-print, the final version can be found in the \\ Transportation Research Record, Volume 2364, 12-22, 2013.
}

\begin{abstract}
This study examines the impact of driving experience and habits, citation histories, vehicle ownership, and demographics of over 1,000 Americans on their crash risk and safety policy opinions. Model results suggest that increased driver crash probability and decreased support for crash countermeasures correlate with criminal history and high tolerance for risk, both of which are more prevalent among men than women. Non-injury crash involvement (after controlling years of driving, as exposure metrics) appears more common for those with busy lifestyles: those with higher education and more household vehicles. Support for crash safety policies appears largely independent of a person's (and his/her family's) crash history, but linked to gender, marital status, and education levels. Women and lower income households are more likely to support safety policies, while those with higher educational obtainment are generally less likely. Finally, results suggest that unfamiliarity may be a key (but surmountable) barrier to introduction technology-based safety policies like speed limiters.).
\end{abstract}

\section{KEY WORDS}

Crash Risk, Crash Safety, Driving Behaviors, Safety Policies, Human Factors, Red Light Cameras, Automated Speed Enforcement, Breathalyzer Ignition Locks.

\section{INTRODUCTION}

Traffic fatalities are responsible for 1.3 million deaths annually, worldwide (1). While the number of fatalities is falling in many developed nations, total traffic-related deaths are increasing, as emerging economies grow and the pool of drivers and vehicles expands (1). In the US, motor vehicle crashes were responsible for almost 34,000 deaths in 2010 (2). These take young and old alike, accounting for over 16 percent of all deaths of Americans between the ages of 1 and 44 (3). In addition to the human costs, economic impacts are also substantial. AAA estimates that total annual cost of traffic crashes is approximately $\$ 300$ billion more than three times the $\$ 97.7$ billion estimated cost for congestion (4). Such dramatic crash counts and costs make safety a top priority across state and federal transportation agencies, and underscore society's need to understand which factors increase crash risk and injury severity. 
In the U.S., police accident reports serve as the basis for crash databases. Only basic information on those involved is provided, such as age, gender, seat position, and belt use. When crash records are linked to network and vehicle features, researchers are able to predict crash frequencies and severities as a function of roadway and vehicle attributes (see, e.g., 5, 6, 7, 8). The National Highway Transportation Safety Administration's 2007 Motor Vehicle Occupant Safety Survey (9) (MVOSS) assembled data on Americans' driving habits, vehicles, opinions, use of safety restraints, and crash-injury history. The MVOSS does not gather data on non-injury crash experiences or those where others (but not the respondent) were injured. There are no publicly available U.S. databases that capture the crash histories of those involved.

To help address this clear gap in information and understanding, over 1,000 Americans were surveyed regarding their crash experiences, driving habits, annual miles traveled, traffic citation histories, crash histories of family members and friends, vehicle ownership, and demographics. This new data set allows this work to focus on who is most crash prone, and relationships between crash histories, risk-taking behaviors, and various demographic factors.

The survey pursued here also polled respondents on their traffic safety policy opinions, including reactions to mandatory breathalyzer ignition locks and vehicle impoundment for DUI (driving under the influence) offenders, red-light-camera applications, automatic speed enforcement (ASE) technologies, and vehicle governors to limit top driving speeds. Public opinion is important for policy evolution. Relevant here is the fact that almost one third of all U.S. traffic fatalities involve alcohol-impaired driving (10), and alcohol-related crashes have been estimated to account for 22 percent of all U.S. crash costs (11). There has long been strong public support for prevention (including use of ignition interlocks) and harsher penalties against drunk-driving offenses, particularly for repeat offenders (12). Currently, 32 states have vehicle impoundment/confiscation statutes and 15 states require all first time DUI offenders to install breathalyzer ignition interlocks on their vehicles (13). The data obtained from this survey allows this paper to examine the factors which influence a driver's opinion on crash safety policies. The following discussion introduces the new data set and various modeling results.

\section{DATA DESCRIPTION}

The data for this work come from a nation-wide U.S. survey designed by University of Texas at Austin researchers and distributed via Survey Sampling International in January 2012. Respondents represented 49 of 50 states (all but South Dakota) and a wide range of rural and urban areas (population densities from 0.49 persons $/ \mathrm{mile}^{2}$ to 93,367 persons $/ \mathrm{mile}^{2}$ ). As noted earlier, the survey questioned respondents about their driving experiences and habits, annual miles traveled, traffic citation histories, crash histories, vehicle ownership, safety policy opinions, and demographics ${ }^{1}$. Due to missing and invalid responses for key survey questions, 3.4 percent of the 1044 responses were discarded for a final analysis sample size of $n=1009$ American adults (ages 18 and over). The original respondent pool was designed to oversample a highly vulnerable crash group: motorcycle riders (as described in 14). Thus, sample correction factors were developed based on household motorcycle ownership rates from the 2009 National Household Travel Survey (NHTS) (15), as well as respondent gender and educational attainment (16), so that results better reflect the adult U.S. population Lower educational attainment levels were under-represented in the original sample, thus attainment levels were weighted to match that of the 2011 Census, with 13.6 percent of respondents having less than a high school degree, 30.3 percent achieving a high school diploma or its equivalent, 28.4 percent acquiring some college education, 18.0 percent obtaining a Bachelor's degree, and 9.6 percent possessing a graduate or professional degree. Table 1 shows summary statistics for many (population-corrected) responses of particular interest.

\footnotetext{
${ }^{1}$ Complete survey form available at http://www.caee.utexas.edu/prof/kockelman/public_html/SURVEY_UScrashhistories_Spring2012.pdf.
} 


\section{Sample Demographics}

After weighting, various sample demographics appear to align reasonably well with U.S. values. For example, the average (sampled) driver has been licensed for 27.4 years and is 47.3 years old, slightly older than the 45.5 average age of licensed U.S. drivers (17). Half (49.6 percent) the (sample-corrected) respondents are female and 57.6 percent are married, compared to the 52 percent of adults reported as married in the 2009 American Community Survey (ACS). The average sample household consists of 2.76 people (slightly larger than the 2.59 reported in the 2010 Census) and owns 1.72 vehicles (slightly more than the 1.68 ownership rate reported by the 2010 Census). Approximated from surveyed income brackets, the median sample household income is $\$ 47,000$, slightly lower than the median $\$ 49,777$ reported by the 2010 Census. Interestingly, 23.8 percent of single male respondents reported having been convicted of a misdemeanor or felony, versus $11.8 \%$ of single females, $10.3 \%$ of married males, and $8.2 \%$ of married females.

\section{Respondents’ Driving Experience and Habits}

As shown in Table 1, the (weighted) average respondent drove 11,922 miles per year (VMD) and rode as a passenger for 3888 miles per year, for a total of 15,810 annual person-miles traveled (PMT). These figures are higher than the 10,574 average annual VMD and 13,187 average annual PMT reported in the 2009 NHTS (15). However, the sample average annual VMD is lower than the 14,274 annual VMD per licensed driver, as reported by the U.S. Office of Highway Policy Information (18). Average (sampled) VMD and PMT vary by gender and marital status, with married males driving the most each year, on average, and married females accumulating the most passenger miles each year. Such exposure differences can and do play into crash experience differences.

In addition to VMD and PMT, many driving history and lifestyle habit variables vary with gender and marital status. As shown in Table 1, the average single male in the (weighted) sample has 2.5 times the driver's license revocation rate as his married counterparts (and twice that of his female counterparts) and has received three times as many traffic citations as his married counterparts (four times as many as his female counterparts). Single men are more than twice as likely to have a criminal history, when compared to the three other groups. Problematic driving and criminal histories seem to correspond with risky driving habits, since just 69.9 percent of single men report "always" wearing a seat belt -- versus 81.0 percent of all respondents. Another 9.1 percent of all respondents claimed to buckle up most of the time, for a total seat belt use rate comparable to the 85 percent overall seat belt use rate reported in the 2010 National Occupant Protection Use Survey (NOPUS) (19).

Some habits vary quite a bit by gender: For example, women are 50 percent more likely than men to text messages while driving, while the average male respondent consumes more than twice the number of alcoholic beverages as women each week. Married persons appear to be more health-conscious than their single counterparts, exercising an additional 0.7 hours per week on average and being less likely to smoke while driving. However, married drivers are more likely to speed than their single counterparts, with 45.7 percent of married persons reporting regularly driving above the speed limit, as compared to 33.5 percent of unmarried drivers. Such differences may tie to presence of children in the household and more complex household schedules, and they can mean important differences in crash frequency and type.

\section{Respondents' Crash Experiences}

Though (police-recorded) crashes occur just once every 446,000 miles of U.S. travel per 2009 FHWA Travel Volume Trends and 2009 National Automotive Sampling System General Estimates System (NASS GES), on average, 40.4 percent of the (weighted) respondents report having been involved in at least one injury-free crash, and 16.9 percent have been involved in at least one injurious or fatal crash. It is important to note that the sample may be inherently biased since the survey cannot reach anyone who 
has died in a crash. While crash experiences will rise with age (thanks to rising exposure over one's lifetime), 55.3 percent of respondents (average age of 47 years) have not (yet) directly experienced a crash. The shares of respondents involved in $0,1,2$, or 3 more injury and non-injury crashes are shown in Figure 1, according to the respondent's role in the crash (driver or passenger). Given these statistics, the sample's injury experience appears lower than the 26 percent of persons 16 years of age and older who reported self-injury in a motor vehicle crash (or 22 percent, when excluding crashes as pedestrians or bicyclists) back in the 2007 MVOSS (9).

While fatal crashes occur only every 100 million VMT in the U.S. (20), 2.6 percent of (weighted) respondents have had at least one immediate family member die in a crash, 8.3 percent have had at least one endure life-threatening injuries, and 16.3 percent have had at least one experience other (non-lifethreatening) injuries. Such high rates of crash injuries and fatalities among immediate family members underscore the value of identifying factors that influence crash risk, and quantifying their impacts on risk.

Surprisingly, the relatively problematic driving records of single males do not appear to translate to crashproneness. In both injury and non-injury crashes, single male drivers appear somewhat more crash-prone than their female counterparts (14.1 percent more non-injury crashes and 19.4 percent more injury crashes in single males than single females on average), but also less crash-prone than married drivers of both genders (with the exception that single male drivers are more likely to be repeat-crashers than are married male drivers). When isolating injury crashes (since those have higher costs than non-injury crashes), men are more likely to have been involved in at least one crash as a driver, as compared to women. However, men report driving 20.5 percent more, on average, and married women seem to have the highest propensity of repeat involvements in injury crashes as drivers, with 7.1 percent reporting two or more injury crash experiences, versus just 3.0 percent of single men, 2.1 percent of married men, and 1.3 percent of single women. Of course, the average married woman is older than the average single woman (48.4 vs. 42.1 years of age, respectively), and thus presumably has more lifetime crash exposure.

The survey also asked respondents for the primary reason behind their crashes, with responses shown in Figure 2, by crash type (injurious versus non-injurious). Driver inattention or distraction (and thus error) is the most commonly cited reason, for both injurious and non-injury crashes, underscoring current concerns surrounding the seriousness of distracted driving (see, e.g., 21). Driver fatigue, vehicle malfunction, influence of drugs and/or alcohol, reckless driving, confusing roadway signs, and poor pavement condition are more common reasons given for injury crashes than for non-injury crashes, accentuating the graveness of such habits and circumstances. On the other hand, crashes caused by poor weather conditions tend to be injury-free, consistent with previous findings that such conditions are associated with fewer fatal crashes, as drivers are more like to stay at home and/or slow down as a precaution $(22,23,8)$. Respondents also cited other primary reasons for crashing not listed in the survey, including dysfunctional traffic signals and unexpected animal or pedestrian crossings.

\section{MODEL RESULTS}

While the data description provides general insight into the respondents' crash involvement, regression models allow quantification of individual variables' effects on crash risk and safety policy opinions. Unlike many previous studies which examine crash-specific variables' (e.g., location and vehicle attributes, which vary from crash to crash) contribution to crash risk, these models focus on driver traits (e.g., driving habits and socioeconomic factors) that are relatively consistent from crash to crash. Discrete choice models are employed here both for crash count estimation and safety policy opinion prediction, discussed in detail in the sections below.

\section{Crash Counts}


Researchers generally forecast crash frequencies using discrete models for crash counts over periods of a year. Here, the focus is on forecasting a respondent's past crash history. Such models implicitly involve a crash rate, and include the Poisson, negative binomial (NB), zero-inflated Poisson and NB (ZIP and ZINB) specifications (see, e.g., 24). The Poisson model serves as a starting point for many studies (e.g., 25), but restricts the mean and the variance of any site's counts to be identical (24). The NB model can handle over-dispersion common in crash data and so is used here (24). Common forms of the NB model include NB1 $(\mathrm{P}=1)$, which takes the Poisson parameter for each observation and replaces it with a gamma-distributed error term with mean 1 and variance $\alpha$, keeping the variance a simple multiple of the mean (26). The NB2 ( $\mathrm{P}=2)$ model, on the other hand, maintains a quadratic relationship between the variance and the mean (26). ZIP and ZINB specifications are also common for data settings with a preponderance of zeros, such as when studying counts of severe and fatal crashes, since these tend to be rare events. ZI modeling examples include crash counts along two-lane rural highways (27), crashes involving pedestrians (28) and impact of roadside features on frequency of run-off-roadway crashes (29), and much more.

The crash experience analysis performed here tested NB1, NB2, and ZINB models (as described in, e.g., 30), and as estimated with Stata statistical software), in order to predict the number of crashes (of various types) that individuals had experienced over their lifetimes. The ZINB model was not statistically preferred to the NB models in any of the regressions attempted and the NB2 model provided better statistical fit (higher log pseudo-likelihood values) relative to the NB1 model, so the standard NB2 routine was employed to estimate the crash risk of respondents, both as drivers and as passengers. Initial model specifications revealed statistically significant differences in top regressors for driver crash propensity based on outcome severity, leading to final driver crash models segmented for count of injurious vs. non-injurious crashes, using a years-of-driver-licensure as the exposure variable (rather than VMD, which did not perform as well as licensed years [as a measure of exposure] and is not known for the respondent's lifetime).

In contrast, the passenger crash count results seemed independent of outcome severity, so only one model was estimated using respondents' age as the exposure variable. In all cases, the NB2 model was statistically preferred to a Poisson specification (thanks to overdispersion parameter, $\alpha$, values significantly different than zero, as shown in Table 2). All relevant driving experience and history, lifestyle and habits, environmental and demographic characteristics were tested as regressors for the count models. However, crash-specific variables such as location attributes and vehicle attributes (which vary from crash to crash) are unobserved and contained in the error term. Statistically significant regressors (at the .10 significance level) were retained in all three sets of results, as shown in Table 2.

Table 2's incident rate ratios (IRRs) are calculated as $\operatorname{EXP}\left(\beta_{k}\right)$, where $\beta_{k}$ is the coefficient of the independent variable, and can be interpreted as the factor change in odds for every unit increase in the respective regressor $k$, holding all other variables constant (31). These IRRs provide a quick basis for comparison for the practical significance of each independent variable, as discussed in more detail below.

\section{Driver Crash Propensity}

Table 2 parameter estimates show how both injurious and non-injurious crash rates (per year of licensure) rise with one's criminal history, higher- as well as lower-than-average indicators for annual VMD, texting while driving, higher vehicle ownership, and higher population density. Based on Table 2's IRR values, one finds that criminal history is the top indicator for more injurious-crash risks, as a driver. In line with Murray et al.'s (32) finding that past convictions and violations increase future crash likelihood of commercial drivers, respondents who have at least one felony or misdemeanor on record are predicted to be 221 and 62 percent more likely to be involved in injurious and non-injurious crashes (per year of licensure), respectively, as compared to drivers with no criminal history (and everything else constant in 
the model). In contrast, moving citations within the last 10 years are associated with an increase only in a driver's non-injurious crash involvement, though by 30 percent per citation. While they do not distinguish crash severities, other studies (see, e.g., 33 and 34) also found positive correlation between previous ticketed offenses and subsequent driver crash risk.

Predictably, due to added roadway exposure, those who report driving more than 15,000 miles per year (as denoted by the HIGHVMD indicator variable) are 82 percent more likely to be involved in an injurious crash, while driving, and 36 percent more likely to be involved in a non-injurious crash than drivers who are currently exposed between 5,000 and 15,000 miles annually. The models also indicate that drivers who drive significantly less than the average driver (those with VMD of less than 5,000 miles as denoted by the LOWVMD indicator variable) are also at increased risk for both injury and non-injury crashes. Perhaps due to a lack of driving confidence and familiarity, drivers who drive less than 5,000 miles annually are predicted to be 138 percent more likely to experience an injury crash and 43 percent more likely to experience a non-injury crash, while driving (and per year of licensure) as compared to drivers who drive between 5,000 and 15,000 miles per year, ceteris paribus.

While controlling for VMD, those with a commercial driver's license are predicted to have 104 percent greater risk of being involved in an injury crash, while driving each year, a finding echoing the 2008 FARS statistic that large-truck crashes account for 11 percent of U.S. traffic fatalities despite representing just 4 percent of all registered vehicles and 7 percent of VMD (35). The commercial driver's license indicator variable is not significant in the no-injury crash count model, perhaps underscoring the aggressive nature of large commercial vehicles in a crash, where crash partners are frequently injured.

Average sleep hours per night is another variable only statistically significant in the driver's injury-crash count model. Consistent with findings by Cummings et al. (36) and Stutts et al. (37), the model predicts that every added hour of sleep per night is associated with a 15 percent decrease in the probability of one's being involved in an injurious crash (per year of licensure). The absence of the hours slept in the non-injury crash model is consistent with Figure 3, which shows how respondents rated driver fatigue to be 150 percent more likely to be the primary reason behind an injurious crash versus a non-injury crash. According to 2009 FARS and GES data (38), fatigued drivers/drowsy driving is the main cause behind 1.4 percent of all US crashes, but 2.5 percent of fatal crashes and 2.2 percent of injury crashes.

Figure 3 indicates how respondents believe that distracted driving/inattention is the most common reason for both their injury and non-injury crashes, so it is not surprising that distracted-driving habits (such as texting, eating, and listening to music while driving) are predicted to increase driver crash risk, particularly in non-injury crashes. Habitual texting while driving, in particular, is estimated to increase crash rates for both injury and non-injury crashes, by 117 percent and 52 percent, respectively. Multiple studies (e.g., 39 and 40) have linked the sending and receiving text messages while driving to impaired forward and lateral control, delayed reaction times to others' brake lights, and increased misses of lane changes. In addition to distracted driving, regularly driving above the speed limit is associated with higher rates of non-injury crashes ( 52 percent per year of licensure), perhaps due to increased braking distances as a result of faster driving speeds.

Educated drivers appear more prone to non-injury crashes, ceteris paribus, with those obtaining at least some college education predicted to be 69 percent more crash involved (per year of licensure). Drivers in households with children (ages 17 and under) appear more involved in injury crashes than those in alladult households, with each child increasing a driver's injury crash rate by 35 percent. Those in households with more vehicles are also more crash prone, it seems, with injury crash predictions rising 21 percent and non-injury crashes rising 13 percent per added vehicle (the HH_VEHS variable may be partly proxying for motorcycle ownership as it is statistically insignificant in a regression excluding households with motorcycles). The presence of children and more vehicles may be indicators of a more stressful 
schedule, requiring a fair amount of driving and trip complexity, with higher-than-average vehicle occupancy, resulting in higher crash rates. Fortunately, married status counteracts some of this (with married men estimated to be 31 percent less involved in non-injury crashes, per year of license, than the rest of the sample combined).

\section{Passenger Crash Propensity}

In contrast to driver crash count model results, lifestyle and driving history variables were not found to be statistically significant in the passenger crash count model. However, two driving-habit variables were: those who regularly talk on the phone exhibit an 88 percent higher passenger-crash rate, ceteris paribus, while those who habitually smoke while driving are predicted to be 64 percent less involved in crashes, as passengers, per year of age. This drop probably due in part to lower exposure: sampled smokers reported 1044 fewer annual passenger miles (25 percent fewer miles) than those who do not smoke while driving.

Household and demographic characteristics appear to play a bigger role in passenger crash counts. Similar to the driver crash count models, educated passengers in multi-vehicle households, are predicted to be more crash prone, with passenger crash experiences rising 72 percent for those with a graduate or professional degree (after controlling for age and all other covariates shown in Table 2) and 15 percent with an added household vehicle. Intuitively, due to increased carpooling opportunities, each additional licensed driver in the household is associated with 83 percent higher rate, ceteris paribus. As supported by Figure 1, women are 92 percent more crash prone as passengers than men, which is partly attributable to the 7.2 percent more passenger miles women travel each year compared to men. Lastly, members of households with income of $\$ 50,000$ or less (indicated by the LOWINCOME variable) are estimated to have 70 percent higher crash rates, as passengers, than those in households making over $\$ 50,000$ a year. This result is consistent with findings by Chen et al. (41), who concluded that drivers from lower socioeconomic areas face higher crash rates, as compared to drivers from higher status areas, after controlling for driving exposure and population density.

\section{Safety Policy Opinions}

In addition to questions about respondents' crash histories, the survey also polled the sample on five crash reduction/prevention measures: red light cameras, ASE technologies, mandatory speed governors, breathalyzer ignition locks (for single and repeat DUI offenders), and vehicle impoundment for DUI offenders. This study employs ordered probit (OP) models to identify factors most associated with individual (and ultimately public) support for or opposition to such DUI and speed enforcement measures. Ordered regression models are widely used to study a variety of transportation policy opinions, ranging from employee parking policies (42) to roadway pricing policies (e.g., 43, 44). However, within the context of transportation safety measures, such models are less common. Rienstra and Rietveld (45) used OP regressions to analyze the acceptance of lower speed limits and speed limiters, and found that people who frequently speed and more educated persons are less likely to accept speed governors. A few years later, Rienstra et al. (46) used an OP specification to understand support for transportation safety policy measures and found that perception of the seriousness of a transportation problem had the most significant impact on such support.

Respondents were asked to rank their support for each policy on a five-point (Likert) scale, ranging from strongly oppose to strongly support. As seen in Figure 3, the three most popular crash reduction measures (mandatory breathalyzer ignition locks for single and repeat DUI offenders and vehicle impoundment) all address drunk driving. Such strong support reflects serious public concern, since use of alcohol and/or drugs significantly increase the severity of crash outcomes $(47,48,49$, and 8 ). A recent Insurance Institute for Highway Safety survey $(50,51)$ also revealed general support for alcohol detection technology in all vehicles, with stronger support from non-drinking female respondents in lower income 
households. While proponents argue that interlocks and vehicle impoundment for DUI offenders decrease recidivism $(52,53)$, critics question the legality of seizing vehicles before the driver has been proven guilty and balk at the high cost of installing mandatory ignition interlocks, an estimated $\$ 432$ million burden on the states $(51,13)$.

Though red light cameras have been estimated to reduce the number of injury crashes by 25 to 30 percent (54) and the economic costs of crashes by 9 to 14 percent (55), the high cost of camera installation and operation, reports of drivers regularly ignoring citations, and public skepticism regarding camera accuracy without police testimony create controversy. While the majority (59.0 percent) of the sample-corrected respondents still in support red-light-camera use, 24.6 percent are opposed.

The least popular crash reduction measures tackle speeding violations. This result is somewhat expected, since 40.5 percent of respondents admitted to regularly driving above the speed limit on freeways. Just over half (54.3 percent) support ASE technologies, while 27.3 percent oppose automatic enforcement. Even among supporters of ASE, the average speed over the speed limit for which automatic ticketing would be acceptable is $10.1 \mathrm{mph}$. Among those opposed, $14.7 \mathrm{mph}$ over the speed limit was considered a serious enough offense for automatic ticketing. Use of speed governors on all vehicles was the least supported policy, with 36.6 percent approving and 40.8 percent disapproving. On average, speed governor supporters thought $82.6 \mathrm{mph}$ was an acceptable maximum speed while speed governor opponents favored $106.3 \mathrm{mph}$ as the maximum vehicle speed. Despite the overall negative view on these speed reduction measures, speed cameras and limiters have been shown to reduce injury crashes by 11 to 58 (56) and 8 to 34 percent $(57,58)$, respectively.

Beyond a simple bivariate analysis of how many supported what, multivariate OP models were estimated (using STATA statistical analysis software). All statistically significant regressors (at the .10 significance level) were retained in the final specifications, with parameter estimates shown in Table

A traveler's past crash experience was found statistically significant only in perceptions of the policy of ignition lock use for repeat DUI offenders. While respondents with more driving-crash experiences are slightly more likely to support this measure, those who have experienced injury crashes attributable to alcohol use are less likely to support ignition locks. It is possible that the respondents themselves were the DUI party in these injury crashes, particularly since one-vehicle crashes are three times as likely to involve a driver under the influence as are multi-vehicle crashes (59).

In addition to being a useful crash count predictor, criminal history is the most consistent indicator for opposing safety policies. Respondents with a felony or misdemeanor on record are less likely to support all policies/regulations examined here (except the case of red light cameras, where the CRIME variable was not statistically significant). Traffic citation history, on the other hand, has mixed effects: Respondents with a history of moving violations are more likely to support breathalyzer ignition locks for DUI offenders, but less likely to support vehicle impoundment and automatic speed enforcement. Retting (60) also found that ASE support was lower among drivers who had previously received speeding tickets. Previous work (e.g., 51, 6) has found women and lower-income populations to be more supportive of traffic safety policies, and those findings are supported here. Generally, respondents with lower risk tendencies (e.g., married women who always wear seat belts and sleep and exercise a fair bit each week) are more supportive of safety policies. Previous studies find that females hold less risky attitudes toward driving, when compared to males $(61,62)$. Even pre-driving age boys (11-16) express more acceptance of driving violations than young girls (63). Parameter estimates suggest that urban residents favor safety policy measures more than rural residents, but more educated respondents (those with at least some college education) are less likely to support the measures, similar to findings by Rienstra and Rietveld (45). 
Some variables are specific to the policy. Consistent with findings by McCartt et al. (51) and Kweon and Kockelman (6), respondents who consume more alcohol each week are less likely to support drunk driving countermeasures. Those who admit to regularly driving above the speed limit are less likely to support ASE and mandatory speed governors, consistent with findings by Rienstra and Rietveld (45).

Perhaps the most interesting result is that, despite the low popularity of mandatory speed governors, those with a commercial driver's license are more likely to support their use (57.6 percent of commercial drivers support speed governors compared to 36.6 percent of all respondents). Many commercial fleet vehicles, particularly large trucks, are already equipped with speed limiters. Commercial drivers are more familiar with the workings and safety benefits of speed limiters, and familiarity often breeds acceptance (e.g., of tolling policies, as noted in Podgorski and Kockelman [44]). The general public's adverse reaction to speed governors may be a fear of the unknown. Education on the benefits of speed limiters and the extent to which they affect one's driving is likely to increase support for the policy.

\section{CONCLUSIONS}

This paper takes a new perspective on crash risk, by assembling and analyzing a crash data set that enables an investigative focus on individuals' crash histories, risk-taking behaviors, and roadway safety opinions. Instead of treating crashes as unrelated incidents, the work examines the role of various demographics and other factors to illuminate who is most crash-prone. The results reinforce existing findings on the increased crash probability that comes with risky behavior and higher risk tolerance, but distinguishes between variables that contribute to serious crashes involving injury and non-serious (but still problematic) injury-free crashes. Indicators of a stressful lifestyle with complex schedules (as indicated by higher educational attainment, more household vehicles, and a higher tendency to speed) are predicted to increase non-injury crash involvement while having no significant impact on injury crashes. While higher risk tolerance (as indicated by criminal histories and dangerous habits such as texting while driving) is predicted to increase a driver's involvement in both injury and non-injury crashes, average hours of sleep are estimated to impact only injury-crash likelihood, highlighting the gravity of drowsy driving. While the case against distracted driving (particularly talking and texting on mobile devices) have been highlighted in recent years (and rightly so, accordingly to the increased crash risk predicted by this study), the case against drowsy driving has received less publicity -- despite potentially devastating crash outcomes. This work also examines public acceptance of various transportation safety policies. Results suggest that attitudes toward risk affect support for policies that reduce drunk driving and speeding. Additionally, women and lower income household are generally more supportive of safety policies, while more educated respondents are less supportive, ceteris paribus. Familiarity with technology, such as speed governors, should help build public support for related policies. In garnering support for a new safety policy, particularly one that involves technology, education is key. Such results should be of interest to those in law enforcement, public safety, policy-making, vehicle and highway design, parents (of young drivers), drivers, and others who seek to reduce crash risk and crash tolls. Regression model results allow society to appreciate which policies may do the most good in reducing the more costly crashes.

The study is not without limitations. In addition to the potential inherent sample bias due to inability to survey those who have died in a fatal crash, survey responses are open to each respondent's interpretation and inconsistencies may exist. For example, it is possible that criminal history and moving violations are under-reported by some respondents, while minor injury crashes maybe misreported as non-injury crashes (and vice versa). In terms of model extensions, it would be useful to know total crash exposure over one's lifetime, rather than having to rely on years licensed and age as exposure variables. But such variables may be impossible to obtain with high degree of confidence. Related to this, insurance records (such as those maintained by the IIHS, for the industry) are a natural starting point for improving accuracy in the crash-experience variable, but these are proprietary. Ultimately, crashes place a heavy toll on developed and developing communities, harming travelers of all ages, destroying expensive property, and often 
delaying those in upstream traffic. A better understanding of what factors play key roles may allow more effective policy and training, to pursue the Improve Safety objective that is core to most transportation department's missions.

\section{ACKNOWLEDGEMENTS}

The authors are grateful to Dan Fagnant, Mobashwir Khan, Yiyi Wang, Xiaoxia Xiong, and Aria Berliner for survey design aide and distribution; Amy Neskar for data collection assistance; SSI for data acquisition support; several anonymous reviewers for their helpful comments; and Annette Perrone for editorial assistance.

\section{REFERENCES}

1. WHO (2010) Global Plan for the Decade of Action for Road Safety 2011-2020. http://www.who.int/roadsafety/decade of action/plan/english.pdf.

2. National Highway Traffic Safety Administration (2010a) Traffic Safety Facts 2009. U.S. Department of Transportation http://www-nrd.nhtsa.dot.gov/Pubs/811402EE.pdf.

3. Xu, J., Kochanek, K., Murphy, S., Tejada-Vera, B. (2010) National Vital Statistics Reports. Deaths: Final Data for 2007. Center for Disease Control. http://www.cdc.gov/NCHS/data/nvsr/nvsr58/nvsr58_19.pdf.

4. Cambridge Systematics (2011). Crashes vs. Congestion - What's the Cost to Society? Prepared for the American Automobile Association, available at http://newsroom.aaa.com/wpcontent/uploads/2011/11/2011_AAA_CrashvCongUpd.pdf

5. Persaud, B., Retting, R., Lyon, C. (2004) Crash Reduction Following Installation of Centerline Rumble Strips on Rural Two-Lane Roads. Accident Analysis \& Prevention 36(6): 1073-1079.

6. Kweon, Y.J., Kockelman, K.M. (2005) Safety Effects of Speed Limit Changes: Use of Panel Models, Including Speed, Use, and Design Variables. Transportation Research Record 1908: 148-158.

7. Zwerling, C., Peek-Asa, C., Whitten, P.S., Choi, S.W., Sprince, N.L., Jones, M.P. (2005) Fatal Motor Vehicle Crashes in Rural and Urban Areas: Decomposing Rates into Contributing Factors. Injury Prevention 11: 24-28.

8. Chen, T.D. and Kockelman, K.M. (2012). The Roles of Vehicle Footprint, Height, and Weight in Crash Outcomes: Application of a Heteroscedastic Ordered Probit Model. Forthcoming in Transportation Research Record.

9. National Highway Traffic Safety Administration (2008) 2007 Motor Vehicle Occupant Safety Survey Volume 4: Crash Injury and Medical Services Report. U.S. Department of Transportation, Washington DC.

http://www.nhtsa.gov/Driving+Safety/Research+\&+Evaluation/2007+Motor+Vehicle+Occupant+Saf ety+Survey

10. National Highway Traffic Safety Administration (2012b). Traffic Safety Facts 2010 Data: Large Trucks. U.S. Department of Transportation, available at http://wwwnrd.nhtsa.dot.gov/Pubs/811628.pdf.

11. Blincoe, Lawrence J., Seay, Angela G., Zaloshnja, Eduard, Miller, Ted R., Romano, Eduardo O., Luchter, Stephen, and Spicer, Rebecca S. (2002). The Economic Impact of Motor Vehicle Crashes 2000. Report DOT HS 809 446. US Department of Transportation, National Traffic Highway Safety Administration.

12. Lieb, R.C., Wiseman, F., Moore, T.E. (1986) Automobile Safety Programs: The Public Viewpoint. Transportation Journal 25(4): 22-30.

13. Copeland, Larry. (2012, March 6). Safety Group Seeks Ignition Interlocks for All DUI Offenders. USA Today. 
14. Fagnant, D., Kockelman, K. (2012) U.S. Motorcycle Use: Crash Experiences, Safety Perspectives and Countermeasures. Submitted for presentation to the $92^{\text {nd }}$ Annual Meeting of the Transportation Research Board.

15. Federal Highway Administration. (2011) Summary of Travel Trends: 2009 National Household Travel Survey. USDOT report FHWA-PL-11-022, June 2011. http://nhts.ornl.gov/2009/pub/stt.pdf

16. U.S. Census Bureau. (2011) Educational Attainment in the United States: 2011 - Detailed Tables. http://www.census.gov/hhes/socdemo/education/data/cps/2011/tables.html

17. Federal Highway Administration (2010a). Highway Statistics 2010. US Department of Transportation, Available at http://www.fhwa.dot.gov/policyinformation/statistics/2010/.

18. Federal Highway Administration (2010b). Our Nation's Highways: 2010. US Department of Transportation. Available at http://www.fhwa.dot.gov/policyinformation/pubs/hf/pl10023/

19. National Highway Traffic Safety Administration (2010b) Traffic Safety Facts Research Note: Seat Belt Use in 2010 - Overall Results. U.S. Department of Transportation. Available at http://wwwnrd.nhtsa.dot.gov/Pubs/811378.pdf

20. National Highway Traffic Safety Administration (2012a). Traffic Safety Facts 2010 Data: Motor Vehicle Crashes. U.S. Department of Transportation, available at http://wwwnrd.nhtsa.dot.gov/Pubs/811552.pdf

21. Richtel, M. (2009, July 18) Drivers and Legislators Dismiss Cellphone Risks. The New York Times.

22. Khattak, A.J., Pawlovich, M.D., Souleyrette, R.R. and Hallmark, S.L. (2002). Factors Related to More Severe Older Driver Traffic Crash Injuries. Journal of Transportation Engineering 128(3): 243249.

23. Wang, X. and Kockelman, K.M. (2005). Occupant Injury Severity using a Heteroscedastic Ordered Logit Model: Distinguishing the Effects of Vehicle Weight and Type. Transportation Research Record 1908: 195-204.

24. Lord, D., Mannering, F. (2010) The Statistical Analysis of Crash-Frequency Data: A Review and Assessment of Methodological Alternatives. Transportation Research Part A (44): 291-305.

25. Jovanis, P.P., and Chang, H.L. (1986) Modeling the Relationship of Accidents to Miles Traveled. Transportation Research Record 1086: 42-51.

26. Greene, W.H. (2007) Functional Forms for the Negative Binomial Model for Count Data. Economic Letters 99: 585-590.

27. Qin, X., Ivan, J.N., Ravishankar, N. (2004) Selecting Exposure Measures in Crash Rate Prediction for Two-Lane Highway segments. Accident Analysis and Prevention 36 (2): 183-191.

28. Shankar, V.N., Ulfarsson, G.F., Pendyala, R.M., Nebergall, M.B., (2003). Modeling Crashes Involving Pedestrians and Motorized Traffic. Safety Science 41 (7): 627-640.

29. Lee, J., Mannering, F. (2002) Impact of Roadside Features on the Frequency and Severity of Run-offRoadway Accidents: An Empirical Analysis. Accident Analysis and Prevention 34(2): 149-161.

30. Greene, W.H. (2011) Econometric Analysis. $7^{\text {th }}$ Edition, Prentice Hall. Upper Saddle River, New Jersey.

31. Long, J.S., and J. Freese (2006) Regression Models for Categorical Dependent Models Using STATA. $2^{\text {nd }}$ Edition, STATA Press. College Station, Texas.

32. Murray, D.C., Lantz, B., Keppler, S.A. (2005) Predicting Truck Crash Involvement: Developing a Commercial Driver Behavior-Based Model and Recommended Countermeasures. American Transportation Research Institute. Available at http://www.atri-online.org/research/results/OnePager\%20CMVE.pdf

33. Elliott, M.R., Waller, P.F., Raghunathan, T.E., Shope, J.T., Little R.J.A. (2000) Persistence of Violation and Crash Behavior Over Time. Journal of Safety Research 31(4): 229-242.

34. Chandraratna, S., Stamatiadis, N., Stromberg, A. (2005) Crash Involvement of Drivers with Multiple Crashes. Accident Analysis and Prevention, 38(3): 532-541.

35. National Highway Traffic Safety Administration (2010c) Traffic Safety Facts 2008 Data: Large Trucks. U.S. Department of Transportation. Available at http://wwwnrd.nhtsa.dot.gov/Pubs/811158.pdf 
36. Cummings, P., Koepsell, T.D., Moffat, J.M., Rivera, F.P. Drowsiness (2001) Counter-Measures to Drowsiness, and Risk of a Motor Vehicle Crash. Injury Prevention 7(3): 194-199.

37. Stutts, J.C., Wilkins, J.W., Vaughn, B.V. (1999). Why Do People Have Drowsy Driving Crashes? Input from Drivers Who Just Do. AAA Foundation for Traffic Safety. http://www.aaafoundation.org/pdf/sleep.pdf

38. National Highway Traffic Safety Administration (2011) Traffic Safety Facts 2009 Crash Stats: Drowsy Driving. U.S. Department of Transportation. Available at http://wwwnrd.nhtsa.dot.gov/Pubs/811449.pdf

39. Drews, F.A., Yazdani, H., Godfrey, C.N., Cooper, J.M., Strayer, D.L. (2009) Text Messaging During Simulated Driving. Human Factors: The Journal of the Human Factors and Ergonomics Society 51: 762-770.

40. Hosking, S.G., Young, K.L., Regan, M.A. (2009). The Effect of Text Messaging on Young Drivers. Human Factors: The Journal of the Human Factors and Ergonomics Society 51: 582-592.

41. Chen, H.Y., Ivers, R.Q., Mariniuk, A.L.C., Boufous, S., Senserrick, T., Woodward, M., Stevenson, M., Norton R. (2010) Socioeconomic Status and Risk of Car Crash Injury, Independent of Place of Residence and Driving Exposure: Results from the DRIVE Study. Journal of Epidemiology and Community Health 64(10): 998-1003

42. Verhoef, E.T., Nijkamp, P., Rietveld, P. (1996) Regulatory Parking Policies at the Firm Level. Environment and Planning C: Government and Policy 14: 385-406.

43. Verhoef, E.T., Nijkamp, P., Rietveld, P. (1997) The Social Feasibility of Road Pricing: A Case Study for the Randstad Area. Journal of Transport Economics and Policy 31(3): 255-276.

44. Podgorski, K.V., Kockelman, K.M. (2006) Public Perceptions of Toll Roads: A Survey of the Texas Perspective. Transport Research Part A: Policy and Practice 40(10): 888-902.

45. Rienstra, S.A., Rietveld, P. (1996) Speed Behavior of Car Drivers: A Statistical Analysis of Acceptance of Changes in Speed Policies in The Netherlands. Transportation Research 1 (2): 97-1 10.

46. Rienstra, S.A., Rietveld, P., Verhoef, E.T. (1999) The Social Support for Policy Measures in Passenger Transport: A Statistical Analysis for The Netherlands. Transportation Research Part D 4(3): 181-200.

47. Shibata, A. and Fukuda, K. (1994) Risk Factors of Fatality in Motor Vehicle Traffic Accidents. Accident Analysis and Prevention 26(3): 391-397.

48. Krull, K.A., Khattak, A.J. and Council, F.M. (2000) Injury Effects of Rollovers and Events Sequence in Single-Vehicle Crashes. Transportation Research Record 1717: 46-54.

49. Bedard, M., Guyatt, G.H., Stones, M.J. and Hirdes, J.P. (2002) The Independent Contribution of Driver, Crash, and Vehicle Characteristics to Driver Fatalities. Accident Analysis and Prevention 34(6): 717-727.

50. Insurance Institute for Highway Safety (2000) Traffic Engineering Approaches to Reduce Crashes on Urban Arterial Roads. http://www.iihs.org/research/topics/pdf/iihs traffic approaches.pdf

51. McCartt, A.T., Wells, J.K., Teoh, E.R. (2010) Attitudes Toward In-Vehicle Advanced Alcohol Detection Technology. Traffic Injury Prevention 11(2): 156-164.

52. DeYoung, D.J. (1997) An Evaluation of the Specific Deterrent Effect of Vehicle Impoundment on Suspended, Revoked and Unlicensed Drivers in California. California Department of Motor Vehicles, available at http://dmv.ca.gov/about/profile/rd/r_d report/section\%203/171deter $\% 20$ effect $\% 20 \mathrm{veh} \% 20 \mathrm{imp} . \mathrm{pdf}$

53. McCartt, A.T., Leaf, W.A., Farmer, C.M., and Eichelberger, A.H. (2012). Washington State's Alcohol Ignition Interlock Law: Effects on Recidivism Among First-time DUI Offenders. Insurance Institute for Highway Safety Report. Available at http://www.iihs.org/research/topics/pdf/r1168.pdf.

54. Retting, R.A. (2003) Speed Cameras - Public Perceptions in the U.S. Traffic Engineering and Control 44 (3): 100-101.

55. Federal Highway Administration (2005) Safety Evaluation of Red-Light Cameras. US Department of Transportation, available at http://www.fhwa.dot.gov/publications/research/safety/05049/ 
56. Wilson, C., Willis, C., Hendrikz, J.K., Bellamy, N. (2009) Speed Enforcement Detection Devices for Preventing Traffic Injuries. Cochrane Database of Systematic Reviews 2009 (1): 1-51.

57. Perret, K.E., Stevens, A. (1996). Review of the Potential Benefits of Transport Telematics. TRL Report 200, Transportation Research Laboratory, Crowthorne.

58. Várhelyi, A. (1996). Dynamic Speed Adaptation Based Upon Information Technology: A Thereotical Background. Bulletin 142, Department of Traffic Planning and Engineering, University of Lund, Sweden.

59. National Highway Traffic Safety Administration (2012c). Traffic Safety Facts 2010 Data: AlcoholImpaired Driving. US Department of Transportation, available at http://wwwnrd.nhtsa.dot.gov/Pubs/811606.pdf

60. Retting, R.A., Ferguson, S.A., Hakkert, A.S. (2003) Effects of Red Light Cameras on Violations and Crashes: A Review of the International Literature. Traffic Injury Prevention 4 (1): 17-23.

61. Angle, H. Buckley, K., Fearn, A, Goddard, E. (2007). Think! Road Safety Campaign. Annual Survey 2007. London: Department for Transport

62. Fuller, R., Bates, H., Gormley, M., Hannigan, B. (2008) The Conditions for Inappropriate Speed: A Review of Literature 1995-2006. Department for Transport, London.

63. Waylen, A., McKenna, F.P. (2008) Riskey Attitudes Towards Road Use in Pre-Drivers. Accident Analysis and Prevention 40: 905-911.

\section{LIST OF TABLES AND FIGURES}

TABLE 1 Respondents' Driving History and Lifestyle Habits, by Gender and Marital Status TABLE 2 Parameter Estimates of Crash Count Models by Respondent Role and Injury Severity TABLE 3 Parameter Estimates of Safety Policy Opinion Models (OP)

FIGURE 1 Non-Injury and Injury Crash Involvement by Gender and Marital Status

FIGURE 2 Primary Reason for Crash, by Injury Severity

FIGURE 3 Respondent Opinions regarding Safety Policies

TABLE 1 Respondents' Driving History and Lifestyle Habits, by Gender and Marital Status

\begin{tabular}{|c|c|c|c|c|c|c|}
\hline Variable & Description & $\begin{array}{c}\text { All } \\
\text { Persons }\end{array}$ & $\begin{array}{l}\text { Single } \\
\text { Males }\end{array}$ & $\begin{array}{c}\text { Single } \\
\text { Females }\end{array}$ & $\begin{array}{c}\text { Married } \\
\text { Males }\end{array}$ & $\begin{array}{l}\text { Married } \\
\text { Females } \\
\end{array}$ \\
\hline \multicolumn{7}{|c|}{ Demographic Information } \\
\hline AGE & Age of respondent & 47.3 & 41.8 & 42.1 & 54.5 & 48.4 \\
\hline HH_KIDS & $\begin{array}{l}\text { Number of children (17 and } \\
\text { under) in household }\end{array}$ & 0.56 & 0.17 & 0.47 & 0.60 & 0.90 \\
\hline HH_VEHS & Number of vehicles in household & 1.72 & 1.69 & 1.34 & 1.82 & 1.89 \\
\hline $\begin{array}{l}\text { HH_LICDRIVER } \\
\text { S }\end{array}$ & $\begin{array}{l}\text { Number of licensed drivers in } \\
\text { household }\end{array}$ & 2.07 & 1.86 & 1.83 & 2.20 & 2.28 \\
\hline LOWINCOME & $\begin{array}{l}1 \text { if household income is less than } \\
\$ 50,000 ; 0 \text { otherwise }\end{array}$ & $51.2 \%$ & $60.3 \%$ & $78.3 \%$ & $41.8 \%$ & $35.2 \%$ \\
\hline $\begin{array}{l}\text { COLLEGEORM } \\
\text { ORE }\end{array}$ & $\begin{array}{l}1 \text { if respondent has obtained any } \\
\text { college education; } 0 \text { otherwise }\end{array}$ & $56.0 \%$ & $53.8 \%$ & $54.8 \%$ & $57.7 \%$ & $57.0 \%$ \\
\hline GRADPROFDEG & $\begin{array}{l}1 \text { if respondent has a } \\
\text { graduate/professional degree; } 0 \\
\text { otherwise }\end{array}$ & $9.6 \%$ & $10.8 \%$ & $5.6 \%$ & $11.4 \%$ & $9.7 \%$ \\
\hline POP_DENS & $\begin{array}{l}\text { Population density } \\
\left(\text { persons } / \mathrm{mile}^{2}\right)\end{array}$ & 2947 & 2608 & 3141 & 3531 & 2522 \\
\hline \multicolumn{7}{|l|}{ Driving History } \\
\hline
\end{tabular}




\begin{tabular}{|c|c|c|c|c|c|c|}
\hline VMD & Annual miles driven & 11,922 & 12,142 & 11,560 & 13,728 & 10,294 \\
\hline LOWVMD & 1 if $\mathrm{VMD}>15,000 ; 0$ otherwise & $23.3 \%$ & $18.3 \%$ & $25.6 \%$ & $19.4 \%$ & $29.3 \%$ \\
\hline HIGHVMD & 1 if $\mathrm{VMD}<5000 ; 0$ otherwise & $9.7 \%$ & $8.5 \%$ & $6.5 \%$ & $15.8 \%$ & $7.1 \%$ \\
\hline APM & Annual passenger miles & 3888 & 4193 & 3241 & 3402 & 4551 \\
\hline PMT & Annual miles traveled & 15,810 & 16,335 & 14,800 & 17,130 & 14,845 \\
\hline COMMLIC & Possesses commercial license & $9.8 \%$ & $7.9 \%$ & $6.1 \%$ & $17.1 \%$ & $6.9 \%$ \\
\hline LIC_REVOKED & Had driver's license revoked & $12.5 \%$ & $25.5 \%$ & $12.7 \%$ & $10.1 \%$ & $4.7 \%$ \\
\hline VIOLATIONS & $\begin{array}{l}\text { Average number of moving } \\
\text { violations in last } 10 \text { years } \\
\text { (excluding parking citations) }\end{array}$ & 0.94 & 1.98 & 0.54 & 0.74 & 0.62 \\
\hline DEF_DRIVING & $\begin{array}{l}\text { Average number of traffic } \\
\text { courses taken (e.g., defensive } \\
\text { driving) }\end{array}$ & 0.35 & 0.34 & 0.18 & 0.60 & 0.22 \\
\hline \multicolumn{7}{|l|}{ Driving Habits } \\
\hline LISTENMUSIC & $\begin{array}{l}\text { Listens to music/radio while } \\
\text { driving }\end{array}$ & $90.3 \%$ & $89.7 \%$ & $90.4 \%$ & $95.2 \%$ & $86.2 \%$ \\
\hline SEATBELT & Always wears seat belt & $81.0 \%$ & $69.9 \%$ & $83.9 \%$ & $84.5 \%$ & $84.1 \%$ \\
\hline $\begin{array}{l}\text { ABOVE_SPDLI } \\
\mathrm{M}\end{array}$ & $\begin{array}{l}\text { Regularly drives above speed } \\
\text { limit }\end{array}$ & $40.5 \%$ & $34.2 \%$ & $32.8 \%$ & $46.1 \%$ & $45.3 \%$ \\
\hline DRINK & $\begin{array}{l}\text { Drinks (non-alcoholic) beverages } \\
\text { while driving }\end{array}$ & $44.9 \%$ & $40.0 \%$ & $54.3 \%$ & $44.5 \%$ & $42.7 \%$ \\
\hline SMOKE & Smokes while driving & $25.9 \%$ & $29.8 \%$ & $38.1 \%$ & $24.5 \%$ & $16.1 \%$ \\
\hline EAT & Eats while driving & $21.8 \%$ & $20.2 \%$ & $26.6 \%$ & $22.4 \%$ & $19.1 \%$ \\
\hline TALKPHONE & Talks on phone while driving & $23.8 \%$ & $24.5 \%$ & $22.9 \%$ & $21.5 \%$ & $26.2 \%$ \\
\hline HANDSFREE & $\begin{array}{l}\text { Uses hands-free device while } \\
\text { driving }\end{array}$ & $16.8 \%$ & $12.7 \%$ & $18.0 \%$ & $17.9 \%$ & $18.1 \%$ \\
\hline TEXT & Texts messages while driving & $8.3 \%$ & $6.8 \%$ & $11.8 \%$ & $6.2 \%$ & $9.2 \%$ \\
\hline \multicolumn{7}{|l|}{ Lifestyle Habits } \\
\hline CORR_LENS & Wears corrective lenses & $64.3 \%$ & $55.4 \%$ & $69.3 \%$ & $66.9 \%$ & $65.4 \%$ \\
\hline CRIME & $\begin{array}{l}\text { Convicted of misdemeanor or } \\
\text { felony }\end{array}$ & $13.0 \%$ & $23.8 \%$ & $11.8 \%$ & $10.3 \%$ & $8.2 \%$ \\
\hline SLEEP_HRS & Average hours of sleep per night & 7.14 & 7.17 & 7.10 & 7.22 & 7.06 \\
\hline EXERCISE_HRS & $\begin{array}{l}\text { Average hours of exercise per } \\
\text { week }\end{array}$ & 3.25 & 2.78 & 2.94 & 3.65 & 3.45 \\
\hline ALCPERWEEK & $\begin{array}{l}\text { Average number of alcoholic } \\
\text { beverages consumed per week }\end{array}$ & 3.26 & 4.56 & 2.10 & 4.34 & 2.04 \\
\hline
\end{tabular}


TABLE 2 Parameter Estimates of Crash Count Models by Respondent Role and Injury Severity (NB2)

\begin{tabular}{|l|r|r|c|}
\hline \multicolumn{5}{|c|}{ Driver Crash Propensity (Injury Crashes) } \\
\hline \multicolumn{1}{|c|}{ Variable } & Coefficient & t-stat & IRR \\
\hline log likelihood & -464.5 & & \\
\hline Alpha $(\alpha)$ & 1.632 & & \\
\hline YRS_LICENSED & (exposure) & & \\
\hline CONSTANT & -5.187 & -7.26 & \\
\hline Driving History \& Habits \\
\hline COMMLIC & 0.712 & 2.53 & 2.04 \\
\hline LOWVMD & 0.858 & 3.19 & 2.38 \\
\hline HIGHVMD & 0.599 & 1.69 & 1.82 \\
\hline TEXT & 0.775 & 2.12 & 2.17 \\
\hline EAT & 0.500 & 1.82 & 1.65 \\
\hline SMOKE & -0.597 & -2.08 & 0.55 \\
\hline Life Style Variables & 1.165 & 3.77 & 3.21 \\
\hline CRIME & -0.166 & -1.88 & 0.85 \\
\hline SLEEP_HRS & \multicolumn{5}{|c|}{0.299} & 3.25 & 1.35 \\
\hline Household \& Demographic Characteristics \\
\hline HH_CHILDREN & \multicolumn{4}{|c|}{0.189} & 1.87 & 1.21 \\
\hline HH_VEHS & 0.030 & 2.29 & 1.03 \\
\hline $\begin{array}{l}\text { POP_DENSITY } \\
\text { (1000 ppl/mile }{ }^{2} \text { ) }\end{array}$
\end{tabular}

\begin{tabular}{|c|c|c|c|}
\hline \multicolumn{4}{|c|}{ Driver Crash Propensity (Non-Injury Crashes) } \\
\hline Variable & Coefficient & t-stat & IRR \\
\hline log likelihood & -917.7 & & \\
\hline Alpha $(\alpha)$ & 0.550 & & \\
\hline YRS_LICENSED & (exposure) & & \\
\hline CONSTANT & -5.577 & -18.23 & \\
\hline \multicolumn{4}{|c|}{ Driving History \& Habits } \\
\hline VIOLATIONS & 0.263 & 7.62 & 1.30 \\
\hline LOWVMD & 0.360 & 2.23 & 1.43 \\
\hline HIGHVMD & 0.305 & 1.98 & 1.36 \\
\hline ABOVE_SPDLIM & 0.421 & 3.07 & 1.52 \\
\hline TEXT & 0.422 & 1.99 & 1.52 \\
\hline LISTENMUSIC & 0.500 & 2.25 & 1.65 \\
\hline \multicolumn{4}{|l|}{ Life Style Variables } \\
\hline CRIME & 0.485 & 2.22 & 1.62 \\
\hline \multicolumn{4}{|c|}{ Household \& Demographic Characteristics } \\
\hline MARRIEDMALE & -0.377 & -2.42 & 0.69 \\
\hline COLLEGEORMORE & 0.526 & 2.96 & 1.69 \\
\hline HH_VEHS & 0.126 & 1.77 & 1.13 \\
\hline $\begin{array}{l}\text { POP_DENSITY } \\
\left(1000 \mathrm{ppl} / \mathrm{mile}^{2}\right)\end{array}$ & 0.017 & 1.94 & 1.02 \\
\hline
\end{tabular}

\begin{tabular}{|l|r|r|r|}
\hline \multicolumn{2}{|c|}{ Passenger Crash Propensity (All Crashes) } \\
\hline \multicolumn{1}{|c|}{ Coefficient } & t-stat & IRR \\
\hline log likelihood & -490.8 & & \\
\hline Alpha $(\alpha)$ & 2.238 & & \\
\hline AGE & -7.049 & -19.52 & \\
\hline CONSTANT & -0.959 & -3.31 & 0.36 \\
\hline Driving Habits & 0.495 & 2.01 & 1.88 \\
\hline SMOKE & 0.449 & 1.81 & 1.92 \\
\hline TALKPHONE & 0.517 & 1.76 & 1.72 \\
\hline Household \& Demographic Characteristics & & \\
\hline FEMALE & 0.511 & 2.32 & 1.70 \\
\hline GRADPROFDEGREE & 0.232 & 2.55 & 1.83 \\
\hline LOWINCOME & 0.216 & 1.82 & 1.15 \\
\hline HH_LICDRIVERS & 0.034 & 3.44 & 1.03 \\
\hline HH_VEHS & \multicolumn{3}{|c}{} \\
\hline POP_DENSITY (1000 ppl/mile ${ }^{2}$ ) & \multicolumn{4}{|c|}{} \\
\hline
\end{tabular}


TABLE 3 Parameter Estimates of Safety Policy Opinion Models (OP)

\begin{tabular}{|c|c|c|c|c|c|c|c|c|c|}
\hline \multirow[b]{3}{*}{ Variable } & \multicolumn{6}{|c|}{ Drunk Driving Policies } & \multicolumn{3}{|c|}{ Traffic Enforc } \\
\hline & \multicolumn{2}{|c|}{$\begin{array}{c}\begin{array}{c}\text { Breathalyzer } \\
\text { (Single) }\end{array} \\
\end{array}$} & \multicolumn{2}{|c|}{$\begin{array}{c}\text { Breathalyzer } \\
\text { (Multiple) }\end{array}$} & \multicolumn{2}{|c|}{$\begin{array}{c}\text { Vehicle } \\
\text { Impoundment }\end{array}$} & \multicolumn{2}{|c|}{$\begin{array}{l}\text { Red Light } \\
\text { Cameras }\end{array}$} & \multirow{2}{*}{$\begin{array}{r}\text { A } \\
\text { Coeff } \\
\text {. }\end{array}$} \\
\hline & Coeff. & t-stat. & Coeff. & t-stat. & Coeff. & t-stat. & Coeff. & t-stat. & \\
\hline Constant & -1.385 & & -1.902 & & -1.691 & & -0.588 & & 1.475 \\
\hline \multicolumn{10}{|c|}{ Driving History and Experience } \\
\hline TOTALCRASHES & - & - & 0.123 & 2.83 & - & - & - & - & - \\
\hline INJURYCRASHDUI & - & - & -0.699 & -2.05 & - & - & - & - & - \\
\hline LOWVMD & - & - & - & - & - & - & 0.243 & 2.57 & - \\
\hline HIGHVMD & - & - & - & - & - & - & 0.241 & 1.65 & - \\
\hline COMM_LIC & - & - & - & - & - & - & - & - & 0.359 \\
\hline LIC_REVOKED & - & - & - & - & - & - & -0.448 & -2.32 & - \\
\hline VIOLATIONS & 0.046 & 2.16 & - & - & -0.052 & -3.48 & - & - & 0.044 \\
\hline ABOVE_SPDLIM & - & - & 0.179 & 1.65 & - & - & - & - & 0.459 \\
\hline SEATBELT & 0.280 & 2.39 & 0.379 & 3.13 & - & - & - & - & 0.334 \\
\hline \multicolumn{10}{|l|}{ Life Style Habits } \\
\hline CRIME & -0.857 & -3.37 & -0.454 & -2.35 & -0.707 & -4.05 & - & - & 0.358 \\
\hline ALCPERWEEK & -0.015 & -2.60 & - & - & -0.017 & -2.71 & - & - & - \\
\hline SLEEP HRS & - & - & - & - & - & - & 0.089 & 1.86 & 0.454 \\
\hline EXERCISE_HRS & - & - & - & - & - & - & - & - & 0.024 \\
\hline \multicolumn{10}{|c|}{ Household and Demographic Characteristics } \\
\hline $\mathrm{AGE}$ & - & - & 7.14E-03 & 1.93 & - & - & - & - & - \\
\hline FEMALE & - & - & 0.266 & 2.39 & 0.212 & 1.95 & - & - & - \\
\hline MARRIED & 0.306 & 2.72 & - & - & 0.343 & 2.94 & - & - & - \\
\hline COLLEGEORMORE & - & - & -0.306 & -2.39 & - & - & -0.169 & -1.67 & $0.21 \overline{-}$ \\
\hline
\end{tabular}




\begin{tabular}{|c|c|c|c|c|c|c|c|c|c|c|c|c|}
\hline HH_LICDRIVERS & - & - & -0.192 & -2.77 & -0.126 & -2.11 & - & - & 0.115 & 2.54 & - & - \\
\hline $\begin{array}{l}\text { POP_DENSITY (1000 } \\
\left.\mathrm{ppl} / \text { mile }^{2}\right)\end{array}$ & - & - & - & - & 0.016 & 2.41 & 0.015 & 2.69 & - & - & 0.016 & 3.08 \\
\hline \multicolumn{13}{|l|}{ Threshold } \\
\hline$\mu_{0}$ & \multicolumn{2}{|l|}{0} & \multicolumn{2}{|l|}{0} & \multicolumn{2}{|c|}{0} & \multicolumn{2}{|c|}{0} & \multicolumn{2}{|c|}{0} & \multicolumn{2}{|l|}{0} \\
\hline$\mu_{1}$ & \multicolumn{2}{|l|}{0.436} & \multicolumn{2}{|c|}{0.276} & \multicolumn{2}{|c|}{0.473} & \multicolumn{2}{|c|}{0.505} & \multicolumn{2}{|c|}{0.571} & \multicolumn{2}{|c|}{0.436} \\
\hline$\mu_{2}$ & \multicolumn{2}{|l|}{0.876} & \multicolumn{2}{|c|}{0.810} & \multicolumn{2}{|c|}{0.939} & \multicolumn{2}{|c|}{0.980} & \multicolumn{2}{|c|}{1.112} & \multicolumn{2}{|c|}{1.062} \\
\hline$\mu_{3}$ & \multicolumn{2}{|l|}{1.062} & \multicolumn{2}{|c|}{1.432} & \multicolumn{2}{|c|}{1.673} & \multicolumn{2}{|c|}{1.909} & \multicolumn{2}{|c|}{1.987} & \multicolumn{2}{|c|}{1.828} \\
\hline
\end{tabular}



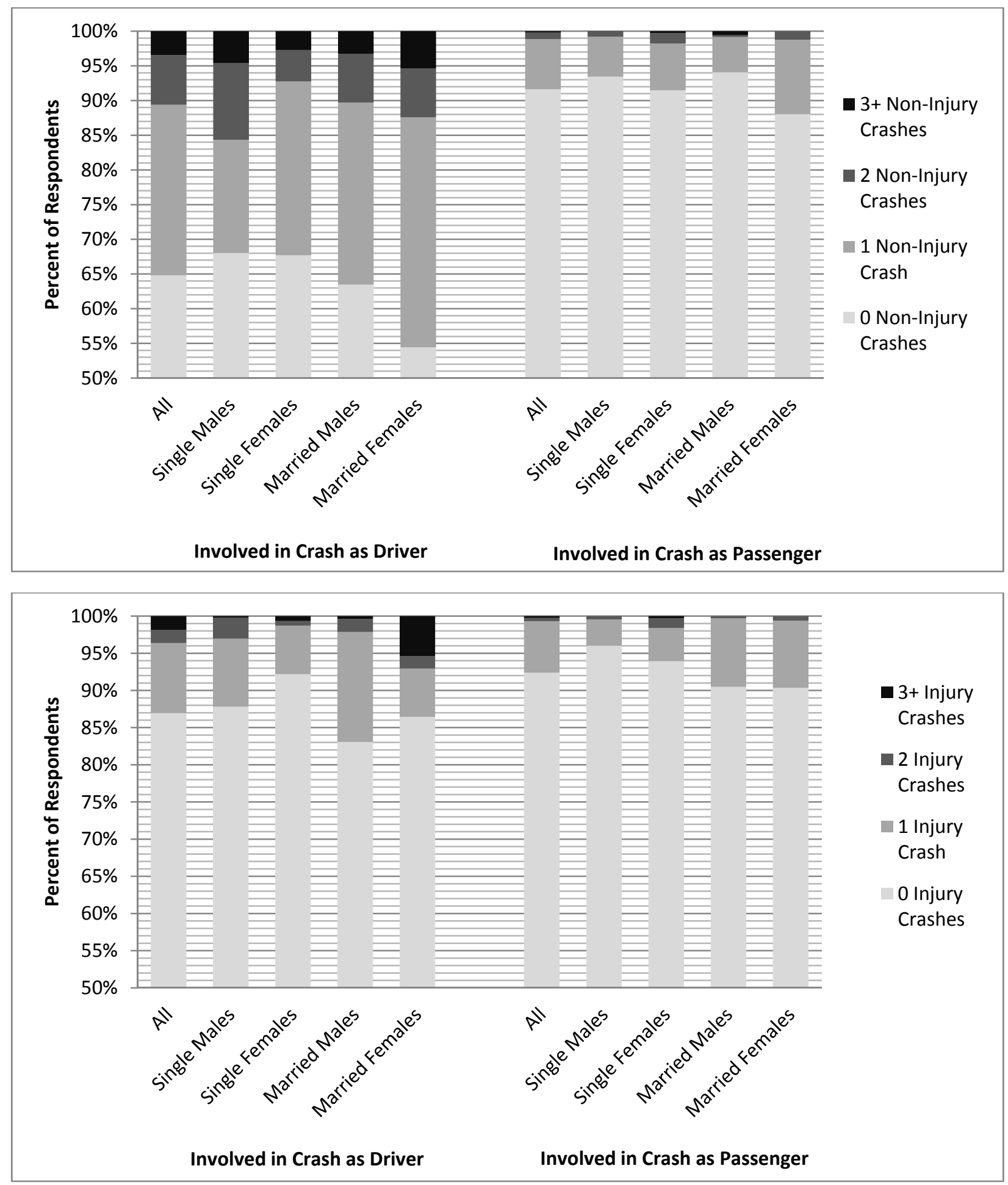

FIGURE 1 Non-Injury and Injury Crash Involvement by Gender and Marital Status 


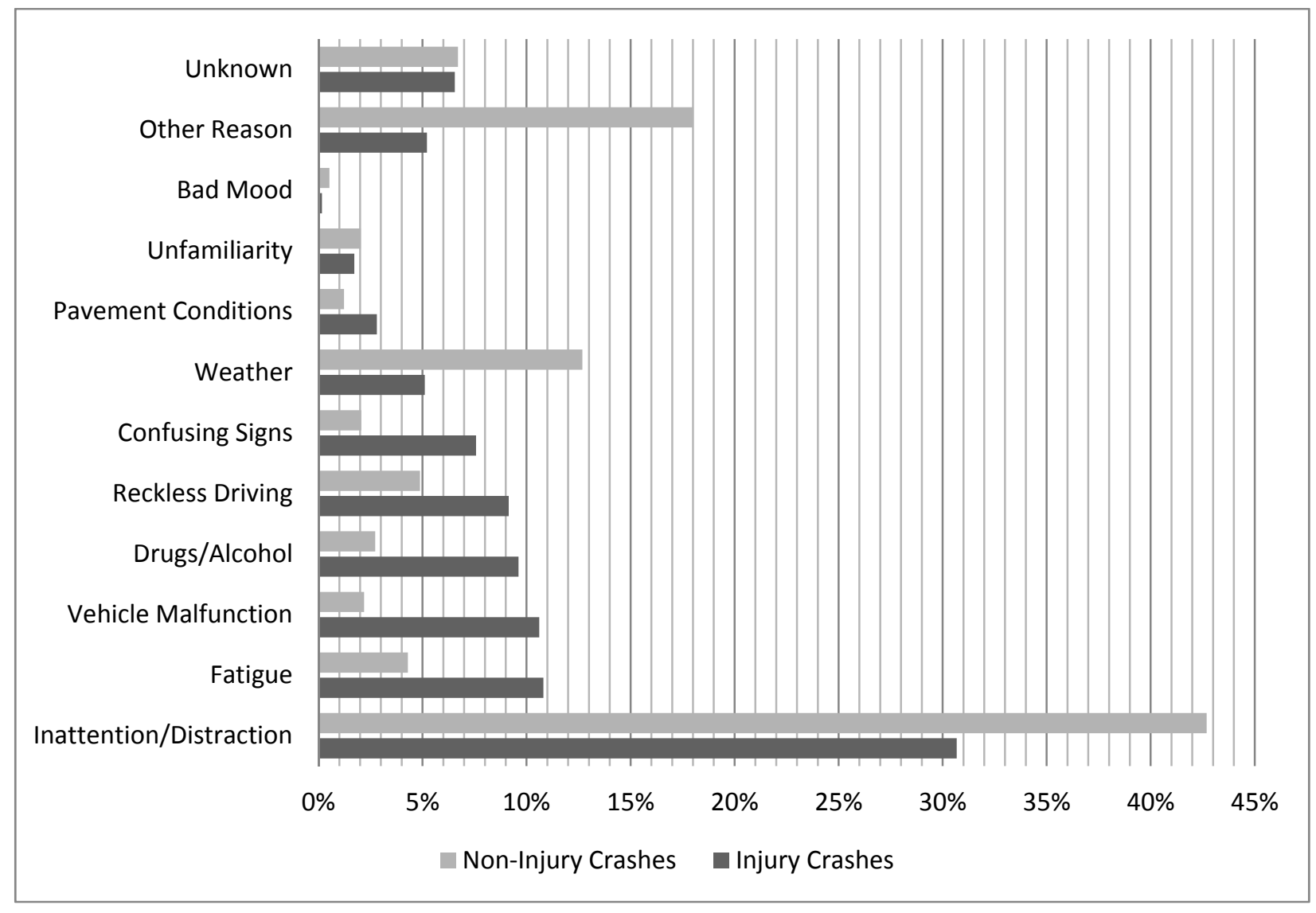

FIGURE 2 Primary Reason for Crash, by Injury Severity 


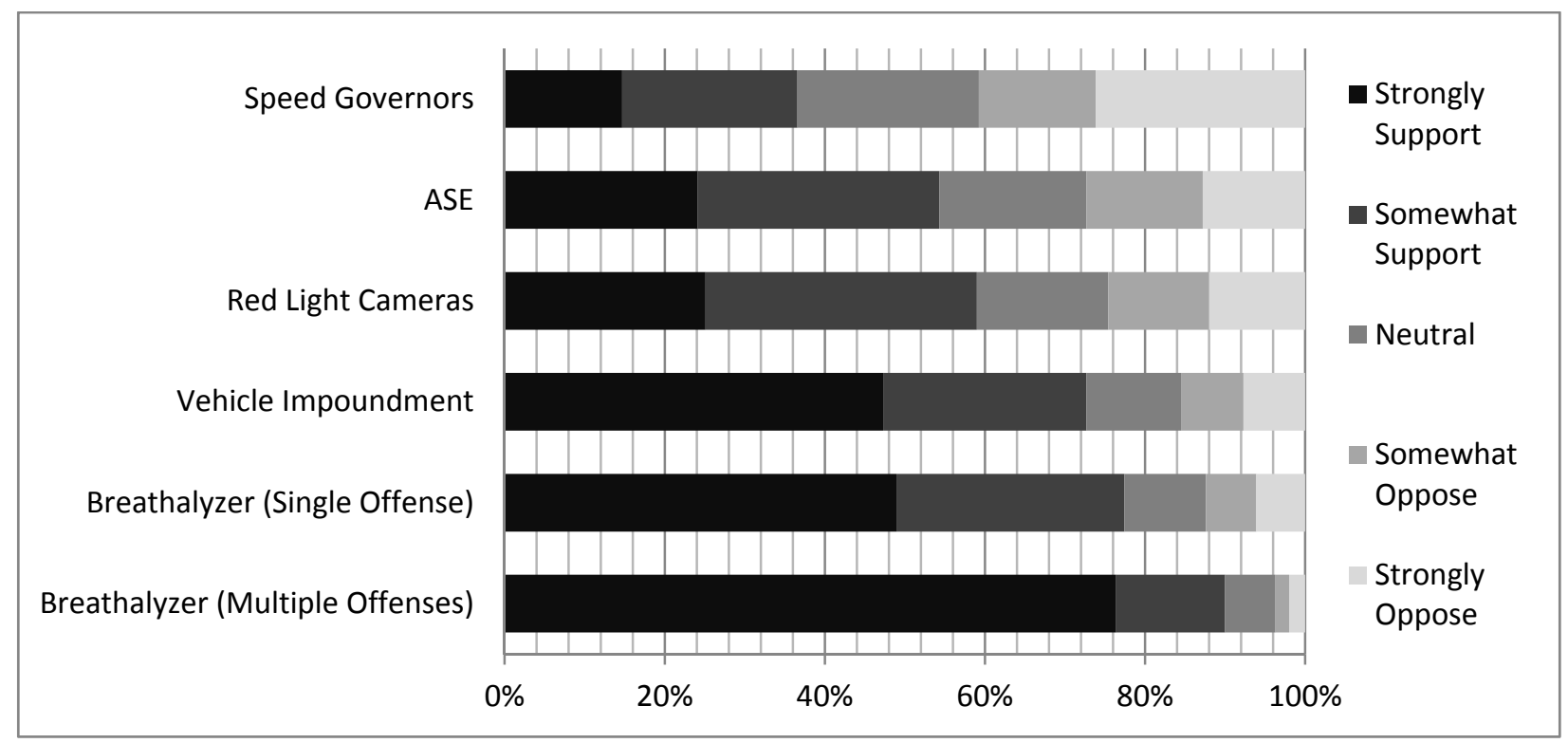

FIGURE 3 Respondent Opinions regarding Safety Policies 